\title{
Measuring spatial equity and access to maternal health services using enhanced two step floating catchment area method (E2SFCA) - a case study of the Indian Sundarbans
}

\author{
Lalitha Vadrevu* and Barun Kanjilal
}

\begin{abstract}
Introduction: Inaccessibility due to terrain and lack of transport leaves mothers travelling for long hours before reaching a facility to deliver a child. In the present article we analyzed the issue of spatial inaccessibility and inequity of maternal health services in the Indian Sundarbans where complex topography and repeated climatic adversities make access to health services very difficult.
\end{abstract}

Methods: We based the article on the health-GIS study conducted in the Patharpratima Block of the Sundarbans in the year 2012. The region has 87 villages that are inhabited, of which 54 villages are in the deltaic (river locked) region and 33 villages are located in the non-deltaic region of the block. We mapped all public and private maternal health facilities and road and water transport network. For measuring inaccessibility, we use the enhanced two-step floating catchment area method (E2SFCA). For assessing inequity in spatial access, we developed an area-based socioeconomic score and constructed a concentration curve to depict inequity. We used ARC GIS 10.3.1 and Stata 11 software for our analysis.

Results: The maternal health facilities are primarily located in the non-deltaic region of the block. On an average it takes 33.81 min to reach the closest maternal health facility. Fifty-two villages out of eighty seven villages have access scores less than the score calculated using Indian Primary Health Standards. Ten villages cannot access any maternal health facility; twenty-six villages have access scores of less than one doctor for 1000 pregnant women; fifty-six villages have access scores less than the block average of 3.54. The access scores are lower among villages in the deltaic region compared to the non-deltaic region. The concentration curve is below the line of equality showing that access scores were lower among villages that were socio-economically disadvantaged.

Conclusions: Maternal health facilities are not equitably accessible to the populations that are disadvantaged and living in the remote pockets of the study region. Provision of a referral transport system along with a resilient infrastructure of roads is critical to improve access in these islands.

Keywords: Maternal health, Enhanced two step floating catchment area method, Geographic information system, Sundarbans, Equity, Gravity models, Spatial accessibility, Concentration curve

\footnotetext{
*Correspondence: vadrevul@gmail.com

IIHMR University, Sanganer, Jaipur, Rajasthan 302029, India
} 


\section{Introduction}

In spite of the decrease in maternal mortality ratio in the past three decades in India, equitable access to institutional delivery services remains to be a vital concern [1]. In this context, physical or spatial inaccessibility due to long travel times, lack of transportation and travel costs, is a major impediment to utilization of institutional delivery services [2]. Studies done in various parts of India have reported on the role of geographical barriers in accessing delivery services at a facility [3-5]. The degree of spatial inaccessibility is greater in rural and socio-economically backward areas. Because of inequitable access to services, mothers travel for hours before they can reach a facility for delivery [6].

Inequitable spatial access to maternal health services has gained significant policy focus in the recent times. Availability, distribution and physical accessibility of health services according to the need of the population determine spatial equity [7]. It has gained a definite place in equity literature on territorial justice [8], spatial equity $[9,10]$ and social exclusion $[11,12]$. Spatial Inaccessibility is also strongly related to social exclusion. The influence of inaccessibility is multi-dimensional, affecting access to economic opportunities, access to health, education, and other services to participate fully in society and geographical inclusion of people with differential biological, economic and social capabilities [13].

From a policy standpoint, allocation of resources and planning of health services are often by geographical region with an aim to ensure equal access to healthcare service. This is particularly important in the case maternal health in rural regions, where inaccessibility is a major cause of maternal mortality. In India, the Indian Public Health Standards (IPHS) mandate that all populations have equal access to healthcare services in the form of availability and spatial accessibility. According to the IPHS guidelines the primary health services delivered through a three-tier system should have a sub centre for a population of 5000 [14], a primary health centre for a population of 30,000 [15] and a community health centre for a population of $1,20,000$ [16]. In spite of robust standards to ensure equal access, issues of low utilization and spatial inaccessibility persist.

For effective planning of health services there is a need for identification of inaccessible areas and to assess the degree of inequity in access. Advanced data on facility locations and better technology for visualization of population level information using techniques like Geographical Information Systems, has made identification of inaccessible and, underserved areas easier. In the present article we use GIS based accessibility measures to examine the issue of spatial inaccessibility and inequity in access to maternal health services in the rural regions of Indian Sundarbans.

\section{Methods}

Study area

The Indian Sundarbans is the world's largest river delta and a UNESCO designated global heritage site. Extending between $21^{\circ} 32^{\prime \prime}$ North and 22 $40^{\prime \prime}$ North Latitude and between $88^{\circ} 05$ East and $89^{\circ} 00$ East Longitude, it is surrounded by the river Hooghly on the west, rivers Ichamati-Herobhanga-Raimangal on the east, Dampier- Hodges line on the north, and the Bay of Bengal on the south. The region constitutes a group of 104 islands in 19 administrative blocks (sub-district level) with a population of approximately 4 million.

Patharpratima is one of the 19 blocks in the region (See Fig. 1). It has 15 Gram Panchayats (GPs); ten of these GPs are water locked (deltaic) while the other five are connected by road (non-deltaic). It has a population of 331,823 spread over an area located in the southwestern part of the Sundarbans, bordered by the reserve forest on the east and the Bay of Bengal on the South. The region has a total of 87 villages that are inhabited, 33 villages located in the non-deltaic region and 54 villages in the deltaic region of the block. A little over half of the households (51 \%) in the block are from Below Poverty Line (BPL) category [17]. The block ranks 8th among 13 blocks in the South Sundarbans in terms of Human Development Index [18].

The region is also subject to repeated climatic disasters and events [19]. The predominantly agrarian community in the region faces many geographic and climatic challenges that disrupt their livelihood options by inundating banks and rendering agriculture lands barren due to salinity. The road and rail network are not extensive and is left damaged during monsoons. People use multiple modes of transport and have to depend on country boats (Bhut Bhuti) to travel across rivers. These geoclimatic factors have a deleterious impact on health outcomes of the population in the region. Studies show that there is a high prevalence of childhood illnesses and morbidity [20]. Both the public and private health systems cater to the maternal healthcare needs of the population of Patharpratima. The public health system in the region consists of a three-tier system of Block Primary Health Centres (BPHCs), Primary Health Centres (PHCs), and Sub-Centres (SCs). Private providers like quacks, traditional healers, and private allopathic physicians also provide health services. The utilization of maternal health services is suboptimal with $47 \%$ of the mothers delivering children at their homes [ibid].

\section{Study design}

The present article is based on the health-GIS study conducted in the patharpratima block of the Indian Sundarbans. The study follows a cross-sectional 


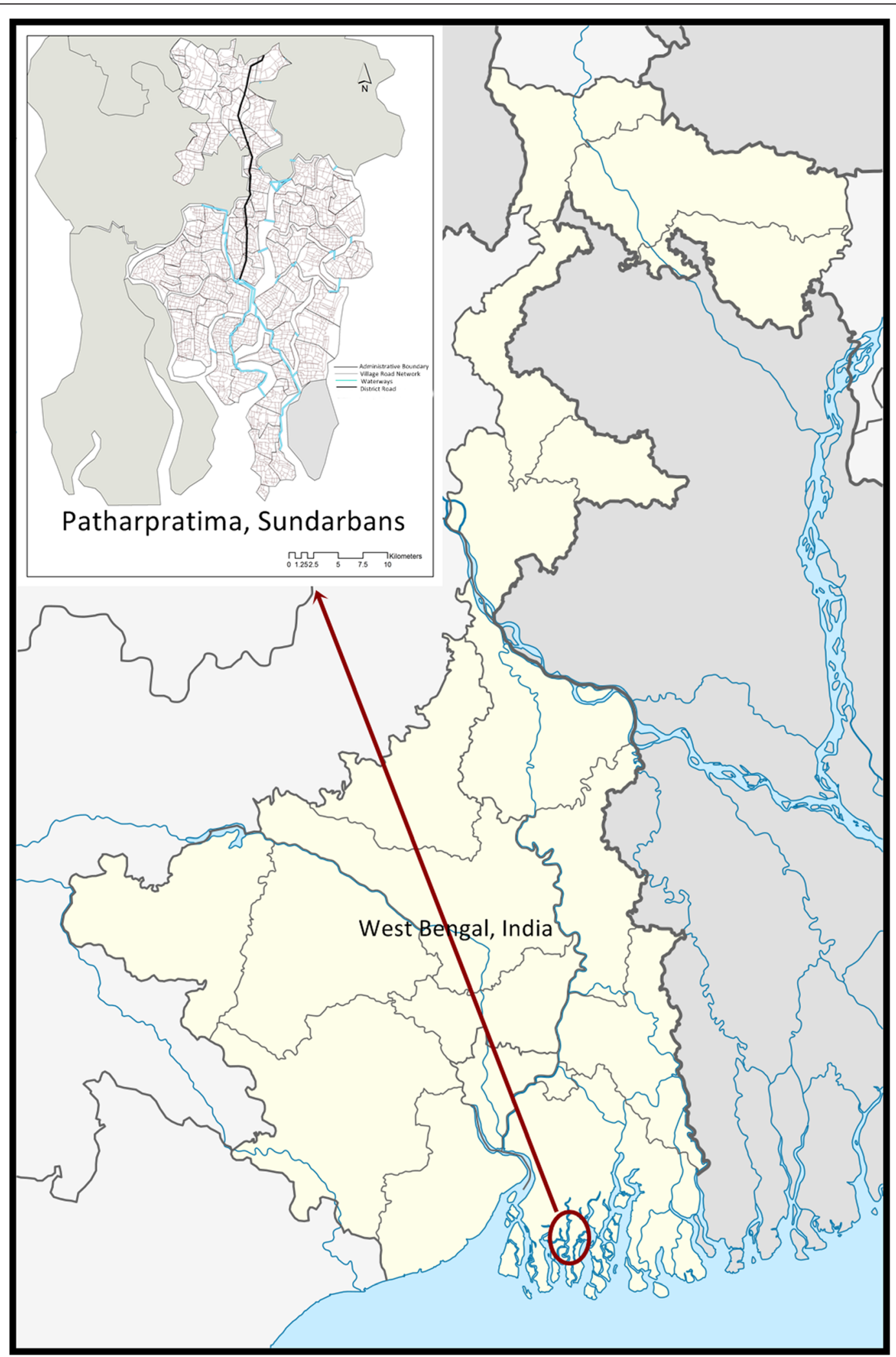

Fig. 1 Patharpratima Block of the Sundarbans 
study design to map the spatial distribution of health facilities and the transportation network in the block. We collected the spatial data of all the public and private health facilities that provide institutional delivery facility, ferry ghat points, water transport network and ancillary health service points in the study region using Garmin Etrex GPS devices in the form of latitudes and longitudes. We considered two types of facilities: public facilities that include block primary health centres and primary health centres, and private facilities that include nursing homes and community delivery centres.

We used villages, the last administrative region of the block, as representatives of the population. The block has a total of 90 villages of which only 87 are inhabited. For the purpose of analysis all these 87 villages were considered. We created the base map of the study region with villages as the last administrative unit by digitizing the census maps. We used the UTM Projection System and, datum WGS 84 in ARC GIS 10 (http://www.censusindia.gov.in/2011census/maps/ atlas/West\%20Bengal.html).

For digitizing the road network in the region, image from Linear Imaging Self Scanning-IV (LISS-IV; spatial resolution $=2.5 \mathrm{~m}$ ) satellite was used (http://nrsc.gov.in). We used secondary data from census 2011 to develop village level socio-economic scores. We used population and village data on household amenities (http://www.censusindia.gov.in/2011census/HLO/HL_PCA/Houselisting-housing-WB.html). We used ARC GIS 10 and Stata 11 for the analysis.

\section{Data analysis}

For measuring spatial access, the most widely used indicator is a provider to population ratio (PPR) [21]. Despite their wide usage, PPRs do not account for inequitable distribution or clustering of facilities, the decreasing likelihood of utilization with increasing distance from the health centre, or inaccessibility within geographical units and cross-border access to care [22, 23]. Measures from newtonian or gravity based models using Geographical Information Systems (GIS) have addressed these issues to a large extent. One of the most widely used gravity based methods for examining the degree of inaccessibility is the Two-step floating catchment area method (2SFCA) [23]. Several versions of this model have been generated in the recent past each attempting to address the limitations of the former [24]. We measure spatial access using Enhanced two-step floating catchment area method (E2SFCA) proposed by Luo and Wang [25]. We used the following parameters for the calculations.

\section{Parameters}

\section{Speeds of transport}

We calculated the travel time based on the speed of travel on various routes. We set the average speed on three types of networks of commute, i.e. Kuccha or Brick road (majorly through motor vans), the district road (through buses) and waterways (through Bhut Bhuti) to $8 \mathrm{Kms}, 45 \mathrm{Kms}$ and $10 \mathrm{Kms}$ respectively (details in the Additional file 1).

\section{Catchment for delivery services}

We set the catchment size for institutional delivery services at $60 \mathrm{~min}$. We set the minimum catchment area at 20 min zero impedance (details in Additional file 1).

\section{Estimated pregnancies per village}

We estimated the number of pregnant women for the year $2012-13$ by multiplying the total population of each village according to 2011 census with the crude birth rate for the state of West Bengal and adjusting it for stillbirths during the year [26]. The following formula was used with a crude birth rate of 18 , factoring for still births by a factor of 0.015 .

Total estimated pregnancies $=$ Total Population

(Crude Birth Rate)/1000) + Estimated Pregnancies 0.015

Figure 2 shows that steps followed for the analysis.

\section{Measuring potential spatial access}

We calculated the travel time $(t)$ from each village centroid (i) to the institutional delivery facility location (j). From the facility location, all population locations/villages $(\mathrm{k})$ that fall within the travel time zone of $60 \mathrm{~min}$ were identified. We calculated the distance weight $\left(\mathrm{W}_{\mathrm{K}}\right)$ by using a continuous distance decay function for travel times between 20 and $60 \mathrm{~min}$ travel times.

If travel time $(\mathrm{t})<=20 \mathrm{~min}$, then the distance weight $\left(\mathrm{W}_{\mathrm{K}}\right)=1$

If travel time $(t)>60 \mathrm{~min}$, then the distance weight $\left(\mathrm{W}_{\mathrm{K}}\right)=0$

If travel time $(\mathrm{t})>20$ or $(\mathrm{t})<=60 \mathrm{~min}$, then the distance weight $\left(\mathrm{W}_{\mathrm{K}}\right)=\left(\frac{60-(\mathrm{t})}{60-20}\right)^{\beta}$

We calculated access scores using two weighting factors $(\beta)$ of 1.5 and 2.0. However we use 1.5 as an appropriate weighing factor for depiction ( $\beta$ ) [27].

For each facility we calculated a physician to population ratio (PPR) using the number of doctors present at the facility $\left(S_{j}\right)$ and a weighted sum of the pregnant women per 1000 population using a) the predicted number of pregnant women per 1000 population $\left(\mathrm{P}_{\mathrm{i}} / 1000\right)$ that year in villages falling within the 60 min catchment 


\section{METHODS - FLOW CHART}

\section{Spatial Inaccessibility}

\section{Measure travel time from all} villages to facility locations $(\mathrm{t})$

Estimate the number of pregnancies for the year in all villages per $1000(\mathrm{Pi} / 1000)$

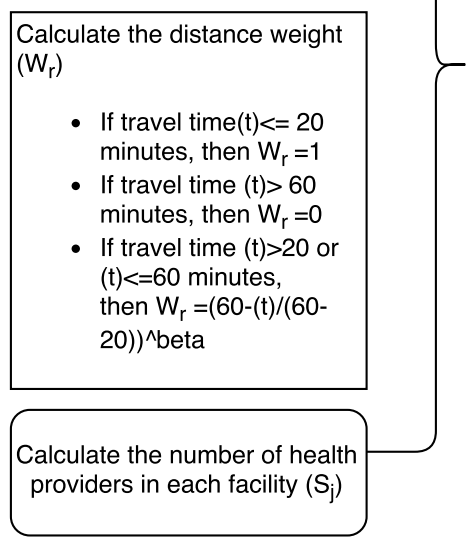

Calculate $R_{\mathrm{j}}$ for all facilities by dividing the number of doctors in the facility by the weighted sum of estimated pregnancies per 1000 in all villages within the catchment area

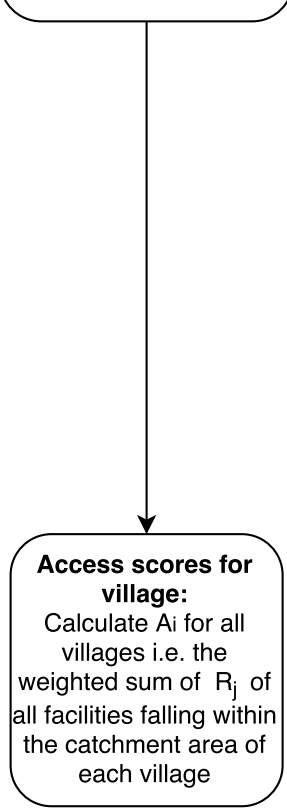

Spatial Equity

Calculate the village level socio-economic status by using principal componant reduction of the following variables

1. Percentage of the females in the village

2. Female population that is literate;

3. Percentage of children below six years of age;

4. Percentage of the population belonging to minority groups like scheduled caste and scheduled tribes;

5. Percentage of the population working;

6. Percentage of the houses that are in a livable condition;

7. Percentage of the households with large household size (households with 6 or more members);

8. Percentage of the households that live in their own house;

9. Percentage of the households with availability of electricity;

10. Percentage of households with availability of latrine;

11. Percentage of the households using banking facility.

Fig. 2 Flow chart - Methods

area, and the distance weight $\left(\mathrm{W}_{\mathrm{K}}\right)$ or travel between service facility ( $\mathrm{j}$ ) and the population cluster(i).

$$
\mathrm{R}_{\mathrm{j}}=\frac{\mathrm{S}_{\mathrm{j}}}{\sum_{\mathrm{d}_{\mathrm{ij}} \in \mathrm{D}^{\frac{\mathrm{P}_{\mathrm{i}}}{1000}} * \mathrm{~W}_{\mathrm{K}}}}
$$

For each population cluster (i), we calculated the sum of the weighted physician to provider ratios of all facility locations (j) within the catchment zone (within drive time of $60 \mathrm{~min}(\mathrm{D})$ ). We used the following equation to develop an village level access score using the provider scores of all facilities in the catchment area.

$$
\mathrm{A}_{\mathrm{i}}=\sum_{\mathrm{d}_{\mathrm{ij}} \in \mathrm{D}} \mathrm{R}_{\mathrm{j}} \mathrm{W}_{\mathrm{k}}
$$

According to IPHS standards, there should a primary health centre with at least two doctors to cater to maternal health needs of the population. For a population 331,823 , there should be at least 10 Primary health centres manned by 20 doctors. If we use this figure as the parameter to evaluate the accessibility of maternal health care facilities, the block should have 20 doctors for the total estimated pregnancies of 
6,095 i.e., a PPR of 3.2 doctors for 1000 pregnant cases. We evaluate the access scores using ARC GIS 10.1 and STATA 11. The origin distance cost distance function in the network analysis module was used to generate the travel times.

\section{Measuring spatial equity}

We calculated the village level/area based socioeconomic scores (SES) using census data. We used the following list of variables for the calculating SES: Percentage of the Female population that is literate; Percentage of children below six years of age; Percentage of the population belonging to minority groups like scheduled caste and scheduled tribes; Percentage of the population working; Percentage of the houses that are in a livable condition; Percentage of the households with large household size (households with 6 or more members); Percentage of the households that live in their own house; Percentage of the households with availability of Electricity; Percentage of households with availability of latrine; Percentage of the households using banking facility.

We conducted a principal component analysis on all of the listed variables. We used the principal component that satisfies the Kaiser criteria and contributes to a major share of the variation in the score depicting village-level/area based SES (details in Additional file 2). The concentration curve displays the share of health, or related variable accounted for by cumulative proportions in the socioeconomic population groups ranked from poorest to richest [28]. For measuring inequity in access between different villages, a concentration curve depicting the cumulative proportion of access scores by the cumulative proportion of area-based socioeconomic index was drawn. The straight line represents the line of equality if the access scores had been equal for all regions irrespective of their socio-economic status.

\section{Results}

Figure 3 shows the distribution of various maternal health facilities, the number of doctors available at the maternal health centres and the service area computed from the shortest travel times. The study region consists of three primary health centres, one block primary health centre, three community delivery centres and six nursing homes. The community delivery centres are located in the river-locked, deltaic regions. All the facilities in the region have 1 to 2 doctors for conducting deliveries. Vast portion of the deltaic or the river locked region falls within the travel time catchment area of 30 to $60 \mathrm{~min}$ or more. The population in each village has to travel a minimum time of $2.60 \mathrm{~min}$ to $78.92 \mathrm{~min}$ to reach a maternal health facility. On an average it takes $33.81 \mathrm{~min}$ to reach the closest facility. The average time to reach the closest facility was 26.62 for villages in the non-deltaic region and $38.21 \mathrm{~min}$ for those in deltaic regions.

In Table 1 we show the distribution of access scores computed using E2SFCA technique using 1.5 and 2.0 as impedance coefficients. The access scores range from 0 to 11.22 for a beta value of 1.5. The access scores range from 0 to 12.44 for a beta value of 2.0. The scores calculated using both values show a similar distribution. In Fig. 4 we show the distribution of access scores using 1.5 as impedance coefficient. Ten out of eighty-seven villages had access scores of 0 indicating no access to a maternal health facility. Twenty-Six out of the eightyseven villages have access scores of less than 1 doctor for 1000 pregnant women. Of these, 20 villages belonged to the deltaic region and 6 to the non-deltaic region. The average access score was 5.92 in the non-deltaic region and 2.13 in the deltaic region. Out of the 87 villages of the block 52 villages had access scores less than the standard using IPHS i.e. 3.2 doctors per 1000 pregnant women, while 56 villages had access scores below block average of 3.54 doctors per 1000 pregnant women.

In Fig. 5 we show the distribution of village level/area based SES. The villages in the non-deltaic region and few of the villages in the deltaic region belonged to the highest SES quintile. A majority of the villages in the northernmost region of the block and the deltaic region belonged to the lowest quintile. In Fig. 6 we show the distribution of access scores mapped against village level SES scores using the concentration curve. The concentration curve lies beneath the line of equality.

\section{Discussion}

The results presented in this article highlight the issue of inaccessibility and spatial inequity of maternal health services in the Patharpratima block of the Sundarbans. We use GIS to measure potential spatial access and equity at a population level. Our research adds to the existing database of studies from China [29, 30], USA [31], Australia [32] and Canada [33], that have explored inaccessibility in accessing health services using GIS techniques. In India, Ranga et.al conducted a study in three districts of Uttar Pradesh of India to map and assess the degree of inaccessibility to outpatient and inpatient services [34]. Our results show that majority of the villages have access scores that are far below the scores required by IPHS standards. Majority of the maternal health facilities are concentrated in the patharpratima gram panchayat and the non-deltaic region of the block. Access scores are also high in regions that have high road connectivity. The villages that are located in the periphery and those that are river locked without access to a concrete road have lower access scores. Our finding that access is lower in remote and rural locations 


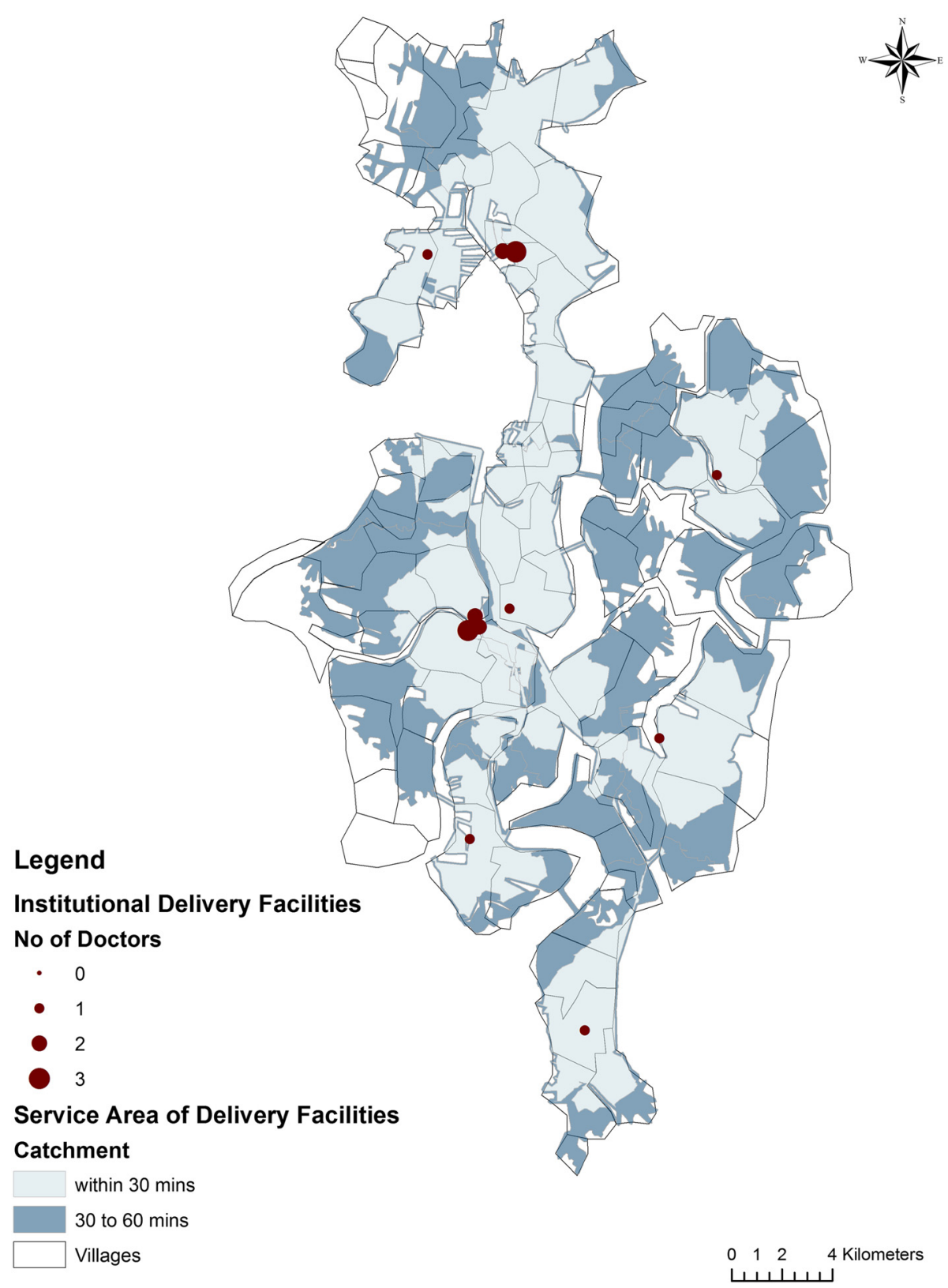

Fig. 3 Maternal Health Facilities and service areas for maternal health services in Patharpratima Block

Table 1 Comparison of Access scores computed using 1.5 and 2.0 as impedance coefficients

\begin{tabular}{lll}
\hline & Access Scores \\
\cline { 2 - 3 } & Beta $=1.5$ & Beta $=2.0$ \\
\hline Mean & 3.545841 & 3.54408 \\
Median & 2.389067 & 2.51659 \\
Min & 11.22187 & 12.44264 \\
Standard Deviation & 0.000000 & 0.000000 \\
\hline
\end{tabular}

is in line with evidence from other similar studies in rural areas that have used GIS $[29,35]$. We find that villages with socio-economically disadvantaged populations face a higher degree of inaccessibility as seen in the concentration curve. The concentration curve lies beneath the line of equality that represents equal access for all regions with different socio-economic scores.

We need to interpret the results from the analysis keeping in mind the various contextual factors that aggravate the problem of inaccessibility in Patharpratima. First, the population residing in the peripheral deltaic pockets of the 


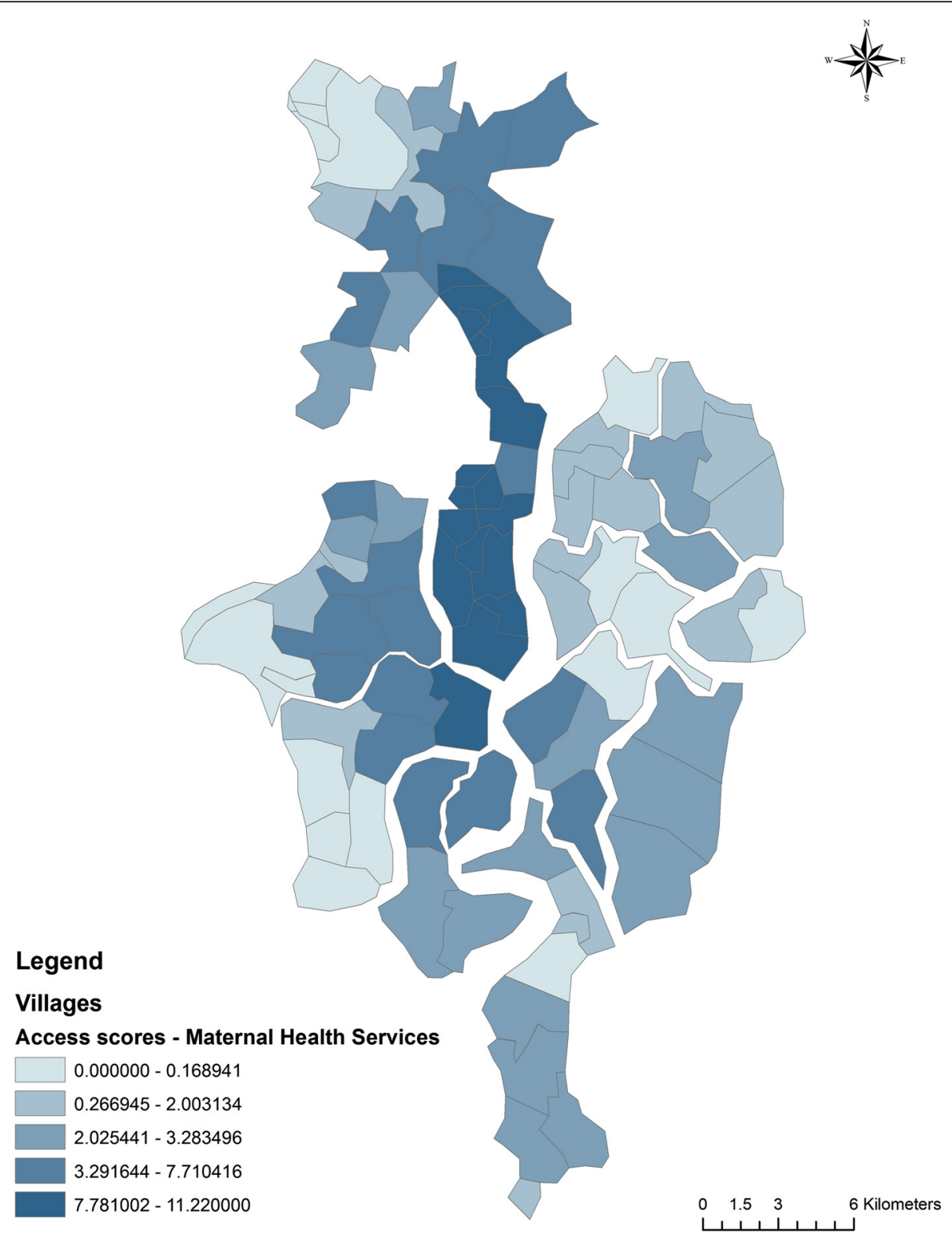

Fig 4 Distribution of Access Scores using E2SFCA

region is surrounded by water bodies and has low road connectivity. The population suffers many challenges that impede access to health services. Their proximity to the sea makes them vulnerable to many seasonal climatic events like cyclones, floods and storms that destroy the road network, housing and even health infrastructure [36]. Flooding during monsoons renders a vast portion of the transport network useless as the kuccha roads fail to put up any defense against climatic adversities. Tidal waves are a regular phenomenon and rise to $7.5 \mathrm{~m}$ height. During the time of low tide, transportation through waterways gets halted. Consequently, the journey to reach a maternal health facility translates into an arduous task for a woman in labour as she has to travel through multiple modes of transport using motor vans, boats and buses.

Second, the vast majority of the population of the block falls below the poverty line. The rural household survey reveals that $51 \%$ of the population falls below poverty line [17]. Our study shows that access to maternal health facilities for regions with socio-economically backward populations was far more inaccessible than the rest. The northern most portion of the block in the nondeltaic region falls in the lowest village level SES quintile and records very low access scores. The problem of inaccessibility to the maternal health facility is compounded by various socio-economic factors. Transport 


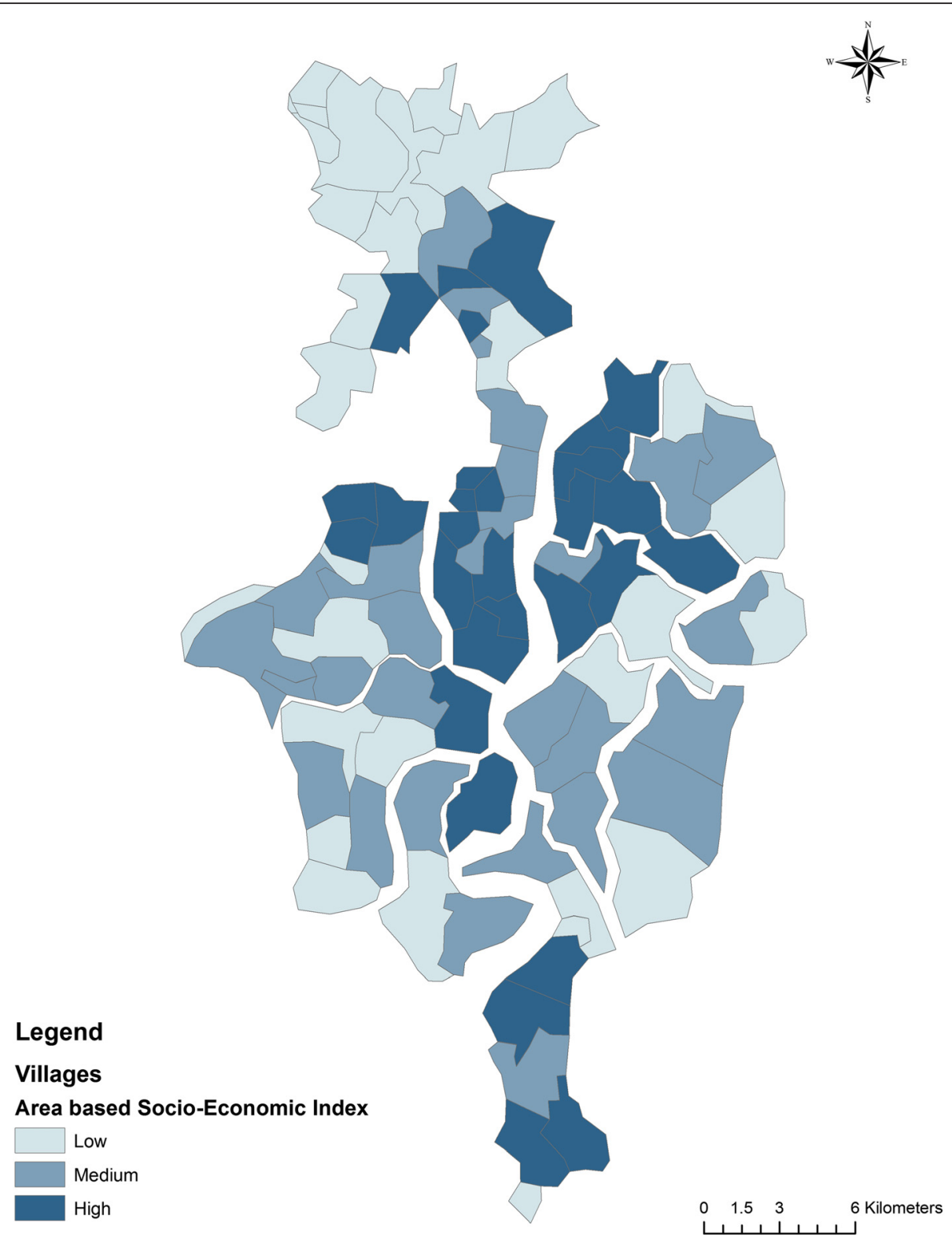

Fig 5 Distribution of Area-Based Socioeconomic Scores

in this complex terrain through multiple modes of transport involves a substantial travel cost, long journey time, inconvenience and opportunity cost in terms of time and daily wages for a poor family. As a result women do not chose to avail institutional delivery services as inaccessibility in this context is both a disincentive and a barrier [6]. These factors also affect the attendance and retention of the health personnel [37, 38]. A study by Kanjilal et al shows that the public health is grossly illequipped to deliver basic maternal and child health services while, many private health facilities function with varying degrees of standards [20]. As a result there is very low utilization of delivery services.

\section{Strengths and weaknesses}

The article has some clear strengths and limitations that need to be kept in mind while interpreting these results. The population level analysis presented in the article tries to make a realistic approximation of the degree of inaccessibility and inequity in access to maternal health services. The analysis has been conducted at the level of the last administrative division in the block improving its reliability in estimating potential access. We have used travel time and not travel distance as it is a better indicator of travel impedance in an area where inaccessible terrain and multiple modes of transport mean longer travel times for relatively shorter distance. Studies 


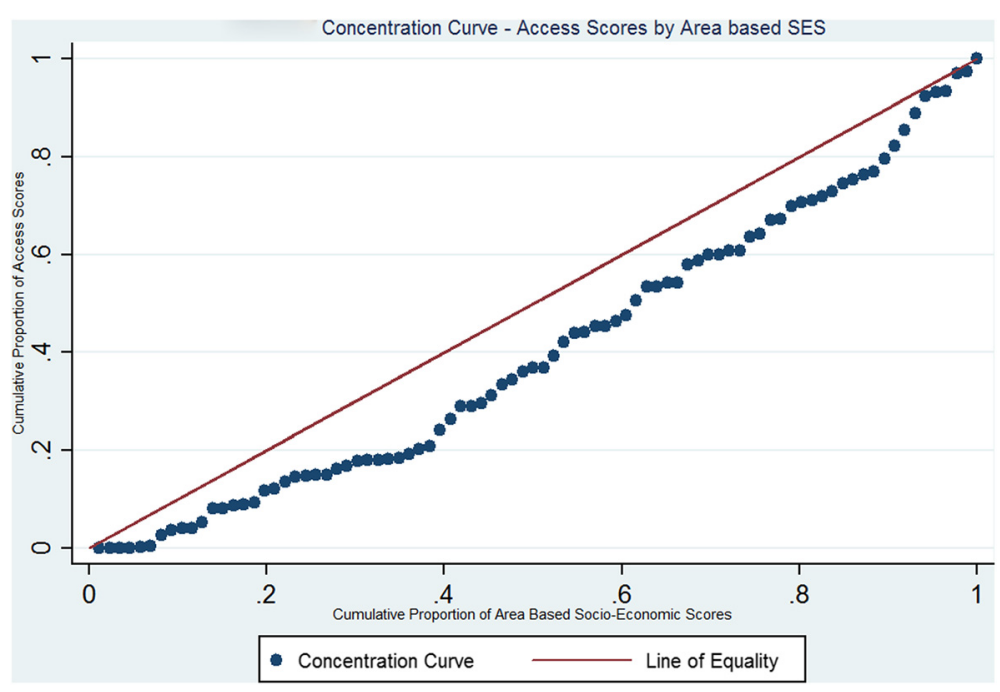

Fig 6 Concentration Curve- Access scores vs Area Based Socio-economic Scores

using GIS have typically used a catchment area of 30 min to determine the degree of inaccessibility [39]. In the analysis presented in this article, we take $60 \mathrm{~min}$ as an ideal travel time based on the IPHS criteria. We base the assumptions used in the analysis on actual utilization data of maternal health services in the region (details in Additional file 1). Also, in the context of rural regions in India, where the travel speeds are extremely low because of lack of transport or road network, a catchment area of 30 min might risk over estimation of the degree of inaccessibility. We use E2SFCA technique, that is a widely used for identifying inaccessible areas and calculating potential access to services. The estimates of potential access are found to be closely associated with perceived access measures in a population, thus improving their validity and application in the analysis of access and equity [40]. Yet, we need to acknowledge that in spite of a high correlation between potential and perceived access, potential access scores need to be validated with real time utilization data to improve the validity of the findings. Even though GIS has found application in terms of identifying inaccessible or underserved regions $[21,41]$, very few studies have been conducted in the context of healthcare in rural regions in India. The present article can contribute immensely to evidence on inequity in access in geo-climatically challenged regions like the Sundarbans.

\section{Conclusion}

Patharpratima Block of the Indian Sundarbans is one of the many geographically isolated regions across the country where geographical and climatic factors impede access to institutional delivery services. Three aspects need attention to ensure that mothers have equitable access to maternal health services: a) Equitable distribution of health facilities b) Efficient referral transport system c) Focus on improving basic infrastructure. There is a need for effective planning in establishing health facilities as per the IPHS norms to ensure equitable distribution of facilities. Efficient referral transport is another crucial step for minimizing the second delay. Although a line of emergency ambulance services were planned by the national health mission in India to reach populations within $30 \mathrm{~min}$, no emergency transport services exist for geographically isolated pockets like the Sundarbans [42].

Along with interventions to minimize travel costs and ensure equitable access, there is a clear need to develop basic infrastructure in rural areas to improve health outcomes. The report on millennium development goals in India highlights the association between infrastructure inputs like roads and electricity on maternal health outcomes [43]. States like Kerala and Tamilnadu that fared well in terms of utilization of maternal health services were also better off than other states in the area of basic infrastructure. Equitable distribution of health facilities, functional network of transport services and provision of basic infrastructure can help in improving health outcomes in these remote islands. It calls for specific measures to develop a resilient transport network and referral transport system along with ensuring equitable distribution of health facilities.

\section{Endnotes}

Gravity Models - These models are based on the concept that interactions between places, people and activities is inversely related to the distance between them, i.e., the entities that are away from each other tend to have lesser interactions. In terms of accessibility, it can 
be interpreted as the population interact or utilize more services from facilities that are closer as compared to those that are far away. In this context the 'distance decay' is often used, meaning the decrease in interactions with increasing distance.

Distance decay - Distance decay is graphically represented by a concave curve plotted with distance on the $\mathrm{x}$-axis and probability of interaction on the $\mathrm{y}$-axis. It is mathematically represented as a negative exponential.

Travel Impedance - It is the cost of traversing a particular path or road network. The cost in measured either in terms of time, money or distance. It represents the willingness to avail health services given the time for travel.

Village Centroid- It is the center of mass (or center of gravity) and may fall inside the feature or outside the feature.

Kuccha Road - Mud road

Gram Panchayat - The administrative region below the block

\section{Additional files}

Additional file 1: Parameter estimation. (DOCX $42 \mathrm{~kb}$ )

Additional file 2: Calculation of area based socio-economic scores. (DOCX $47 \mathrm{~kb}$ )

\section{Abbreviations}

GIS, Geographical Information Systems; E2SFCA, Enhanced two-step floating catchment area method; PHC, Primary Health Centre; BPHC, Block Primary Health Centre

\begin{abstract}
Acknowledgements
We thank all current and former members of Future Health System Research Consortium, who were directly or indirectly involved in conducting the GIS Study. We extend our thanks to RIDDHI UDDHALAK for conducting the study. We also extend our thanks for the inputs from SHIS and community members in the patharpratima block. We express our appreciation of the financial support provided by UK Department of International Development for 'Future Health System Research Consortium' (contract no PO-5467). We extend gratitude for the scientific support extended by the 'Delivering Effective Health Services. Health Services for the Future: A Future Health Systems Consortium' Programme. This document is output from a project funded by DFID for the benefit of developing countries. The views expressed in the article are solely that of the authors and not necessarily that of the partner institutions, DFID or Department of Health and Family Welfare, West Bengal.
\end{abstract}

\section{Authors' contribution}

LV was responsible for the conceptualization, analysis and drafting of the manuscript. BK was responsible for the review of the analysis, interpretation and finalization of the manuscript. Both LV and BK have reviewed and approve the final draft of the manuscript.

\section{Authors' information}

BK is the project coordinator and principal investigator of the Future Health System Research Consortium at IIHMR University. He is also a professor of Health Economics. LV is a senior research associate working in the area of public health at IIHMR University. She works with the Future Health Systems Research Consortium primarily in the area of Health System Research.

\section{Competing interest}

The authors declare that there is no potential conflict of interest.
Received: 16 December 2015 Accepted: 27 May 2016

Published online: 07 June 2016

\section{References}

1. Unicef. Coverage Evaluation Survey. Evaluation. 2009;1-227.

2. Moyer CA, Mustafa A. Drivers and deterrents of facility delivery in subSaharan Africa: a systematic review. Reprod Health [Internet]. 2013 Jan [cited 2014 Dec 31];10:40. Available from: http://www.pubmedcentral.nih.gov/ articlerender.fcgi?artid=3751820\&tool=pmcentrez\&rendertype=abstract.

3. Jat TR, Deo PR, Goicolea I, Hurtig A-K, San Sebastian M. Socio-cultural and service delivery dimensions of maternal mortality in rural central India: a qualitative exploration using a human rights lens. Glob Health Action. 2015;8:24976.

4. Banerjee S, John P, Singh S. Stairway to death. Econ Polit Wkly. 2013;xlvill:123-30.

5. Mazumdar PG, Kanjilal B, Barman D, Mandal A. Revisiting the Role of Geographical Accessibility in Women's Access to Healthcare. Kolkata; Working Paper Series IV; India Series; 2009. p. 1-20. Available from: http:// r4d.dfid.gov.uk/pdf/outputs/futurehealth_rpc/wp-iv.pdf.

6. Gabrysch S, Campbell OMR. Still too far to walk: literature review of the determinants of delivery service use. BMC Pregnancy Childbirth. 2009:9:34.

7. Crooks VA, Andrews GJ. Primary Health Care: People, Practice, Place. Surrey, UK: Ashgate Publishing, Ltd.; 2009 [cited 2015 Sep 14]. 280 p. Available from: https://books.google.co.in/books/about/Primary_Health_Care. html?id=E-LAofcuSGkC\&pgis=1

8. Hay AM. Concepts of equity, fairness and justice in geographical studies. JSTOR. 1995;20:500-8.

9. Berry BJL. David Harvey: Social justice and the city. Antipode. 1974;6:142-9.

10. Stöhr W, Tödtling F. Spatial equity — Some anti-theses to current regional development doctrine. Pap Reg Sci Assoc. 1977:38:33-53.

11. van Wee B, Geurs K. Discussing equity and social exclusion in accessibility evaluations. Eur J Transp Infrastruct Res. 2011;11:350-67.

12. Byrne D. Social Exclusion. McGraw-Hill Education (UK); 2005 [cited 2015 Jun 2]. 202 p. Available from: https:/books.google.com/books?hl=en\&lr=\&id=Rao4 Flw1kgkC\&pgis=1.

13. Church A, Frost M, Sullivan K. Transport and social exclusion in London. Transp Policy. 2000;7:195-205.

14. Directorate General of Health Services. Ministry of health and Family WelFare. Government of India. Indian Public Health Standards (IPHS) Guidelines for Sub-Centres Revised 2012 [Internet]. New Delhi, India; 2012. p. 1-90. Available from: http://nrhm.gov.in/nhm/nrhm/guidelines/indianpublic-health-standards.html.

15. Directorate General of Health Services. Ministry of Health and Family Welfare. Government of India. Indian Public Health Standards (IPHS) Guidelines for Primary Health Centres Revised 2012 [Internet]. New Delhi, India; 2012. Available from: http://nrhm.gov.in/nhm/nrhm/guidelines/indianpublic-health-standards.html.

16. Directorate General of Health Services. Ministry of health and Family WelFare. Government of India. Indian Public Health Standards (IPHS) Guidelines for Community Health Centres Revised 2012 [Internet]. New Delhi, India; 2012. Available from: http://nrhm.gov.in/nhm/nrhm/guidelines/ indian-public-health-standards.html.

17. (2005) Rural Household Survey -2005. In: Panchayat Rural Dev. Dept. http://www.wbprd.nic.in/HtmlPage/bpl.aspx. Accessed 22 Apr 2014.

18. Development \& Planning Department -Government of West Bengal. District Human Development Report - South 24 Paraganas. Kolkata: HDRCC Development \& Planning Department Government of West Bengal; 2009. 1-311 p.

19. Colette A. Case Studies on Climate Change and World Heritage. Paris, France: UNESCO World Heritage Centre; 2007. 1-78 p.

20. IIHMR (2013) How Healthy are the Children of Indian Sundarbans? Kolkata

21. Ricketts TC, Goldsmith LJ, Holmes GM, Randolph RMRP, Lee R, Taylor DH, Ostermann J. Designating places and populations as medically underserved: a proposal for a new approach. J Health Care Poor Underserved. 2007;18:567-89.

22. Guagliardo MF. Spatial accessibility of primary care: concepts, methods and challenges. Int J Health Geogr. 2004;3:1-14.

23. Luo W. Wang F. Measures of spatial accessibility to health care in a GIS environment: synthesis and a case study in the Chicago region. Environ Plan B Plan Des. 2003;30:865-84.

24. McGrail MR. Spatial accessibility of primary health care utilising the two step floating catchment area method: an assessment of recent improvements. Int J Health Geogr. 2012 Jan [cited 2014 Oct 15];11(1):50. Available from: 
http://www.pubmedcentral.nih.gov/articlerender.fcgi?artid=3520708\&tool= pmcentrez\&rendertype $=$ abstract.

25. Luo W, Qi Y. An enhanced two-step floating catchment area (E2SFCA) method for measuring spatial accessibility to primary care physicians. Heal Place. 2009;15:1100-7.

26. Registrar General of India. SRS Bulletin 2012, Sample Registration System. Office of the Registrar General India - Ministry of Home AffairsGovernmentof India. 2012. p. 1-6. Available from: http://censusindia.gov.in/ vital_statistics/SRS_Bulletins/SRS_Bulletin-October_2012.pdf.

27. Wang F. Measurement, optimization, and impact of health care accessibility: a methodological review. Ann Assoc Am Geogr. 2012;102:1104-12.

28. Donnell OO, Doorslaer E van, Wagstaff A, Lindelow M. Analyzing Health Equity Using Household Survey Data - A Guide to Techniques and Their Implementation. 2008.

29. Hu R, Dong S, Zhao Y, Hu H, Li Z. Assessing potential spatial accessibility of health services in rural China: a case study of Donghai County. Int J Equity Health. 2013;12:35.

30. Cheng Y, Wang J, Rosenberg MW. Spatial access to residential care resources in Beijing, China. Int J Health Geogr. 2012;11:32.

31. McLafferty S, Wang F. Rural reversal? Rural-urban disparities in late-stage cancer risk in Illinois. Cancer. 2009;115:2755-64.

32. McGrail MR, Humphreys JS. The index of rural access: an innovative integrated approach for measuring primary care access. BMC Health Serv Res. 2009:9:124

33. Travis Tormala LW (2014) Integrating Spatial and Aspatial Factors in Measuring Accessibility to Primary Health Care Physicians: A Case Study of Aboriginal Population in Sudbury, Canada. J Community Med Health Educ. doi: 10.4172/2161-0711.1000284

34. Ranga V, Panda P. Spatial access to in-patient health care in northern rural India. Geospat Health. 2014;8:545-56.

35. Mobley LR, Root E, Anselin L, Lozano-Gracia N, Koschinsky J. Spatial analysis of elderly access to primary care services. Int J Health Geogr. 2006;5:19.

36. Mazumdar S, Mazumdar PG, Kanjilal B, Singh PK. Multiple shocks, coping and welfare consequences: natural disasters and health shocks in the Indian sundarbans. PLoS One. 2014:9:e105427.

37. Willis-Shattuck M, Bidwell P, Thomas S, Wyness L, Blaauw D, Ditlopo P. Motivation and retention of health workers in developing countries: a systematic review. BMC Health Serv Res. 2008;8:247.

38. Ojakaa D, Olango S, Jarvis J. Factors affecting motivation and retention of primary health care workers in three disparate regions in Kenya. Hum Resour Health. 2014;12:33.

39. Lee RC. Current approaches to shortage area designation. J Rural Heal. 1991;7:437-50.

40. Fone DL, Christie S, Lester N. Comparison of perceived and modelled geographical access to accident and emergency departments: a crosssectional analysis from the Caerphilly Health and Social Needs Study. Int J Health Geogr. 2006;5:16.

41. Delamater PL, Messina JP, Shortridge AM, Grady SC. Measuring geographic access to health care: raster and network-based methods. Int J Health Geogr. 2012;11:15.

42. Ministry of Health and Family Welfare Government of India. NHM Components - Referral Services and Community and Institutions level. Background - Governnment of India. 2013 [cited 2015 Dec 4]. Available from: http://nrhm.gov.in/nrhm-components/rmnch-a/maternal-health/ background.html.

43. Social Statistics Division- Ministry of Statistics and Programme Implementation Government of India. Millennium Development Goals India Country Report 2015. Government of India. New Delhi, India; 2015.

\section{Submit your next manuscript to BioMed Central and we will help you at every step:}

- We accept pre-submission inquiries

- Our selector tool helps you to find the most relevant journal

- We provide round the clock customer support

- Convenient online submission

- Thorough peer review

- Inclusion in PubMed and all major indexing services

- Maximum visibility for your research

Submit your manuscript at www.biomedcentral.com/submit

C Biomed Central 